IZA DP No. 4471

Motivational Goal Bracketing

Alexander K. Koch

Julia Nafziger

October 2009

Forschungsinstitut

zur Zukunft der Arbeit

Institute for the Study

of Labor 


\title{
Motivational Goal Bracketing
}

\author{
Alexander K. Koch \\ Aarhus University \\ and IZA \\ Julia Nafziger \\ Aarhus University
}

\section{Discussion Paper No. 4471 \\ October 2009}

\author{
IZA \\ P.O. Box 7240 \\ 53072 Bonn \\ Germany \\ Phone: +49-228-3894-0 \\ Fax: +49-228-3894-180 \\ E-mail: iza@iza.org
}

\begin{abstract}
Any opinions expressed here are those of the author(s) and not those of IZA. Research published in this series may include views on policy, but the institute itself takes no institutional policy positions.

The Institute for the Study of Labor (IZA) in Bonn is a local and virtual international research center and a place of communication between science, politics and business. IZA is an independent nonprofit organization supported by Deutsche Post Foundation. The center is associated with the University of Bonn and offers a stimulating research environment through its international network, workshops and conferences, data service, project support, research visits and doctoral program. IZA engages in (i) original and internationally competitive research in all fields of labor economics, (ii) development of policy concepts, and (iii) dissemination of research results and concepts to the interested public.
\end{abstract}

IZA Discussion Papers often represent preliminary work and are circulated to encourage discussion. Citation of such a paper should account for its provisional character. A revised version may be available directly from the author. 


\section{ABSTRACT}

\section{Motivational Goal Bracketing*}

It is a puzzle why people often evaluate consequences of choices separately (narrow bracketing) rather than jointly (broad bracketing). We study the hypothesis that a presentbiased individual, who faces two tasks, may bracket his goals narrowly for motivational reasons. Goals motivate because they serve as reference points that make substandard performance psychologically painful. A broad goal allows high performance in one task to compensate for low performance in the other. This partially insures against the risk of falling short of ones' goal(s), but creates incentives to shirk in one of the tasks. Narrow goals have a stronger motivational force and thus can be optimal. In particular, if one task outcome becomes known before working on the second task, narrow bracketing is always optimal.

JEL Classification: $\quad$ A12, C70, D91

Keywords: goals, multiple tasks, motivational bracketing, self-control, time inconsistency, psychology

Corresponding author:

Alexander K. Koch

School of Economics and Management

Aarhus University

Building 1322

8000 Aarhus C

Denmark

E-mail: akoch@econ.au.dk

\footnotetext{
We thank Johannes Abeler, Juan Carrillo, Georg Nöldeke, Hideo Owan, Heiner Schumacher, Frederic Warzynski, and Yoram Weiss for helpful comments and discussions.
} 


\section{Introduction}

People often evaluate consequences of choices separately (narrow bracketing) rather than jointly (broad bracketing) 1 For example, a student might set himself the narrow goals to "achieve a score of $60 \%$ in each exam this term", rather than the broad goal to "get an average score of $60 \%$ over all exams this term". Such narrow goals however seem at odds with maximizing behavior, as Read et al. (1999, p.171) note: "Because broad bracketing allows people to take into account all the consequences of their actions, it generally leads to choices that yield higher utility." We investigate one possible explanation for this puzzle: people bracket their goals narrowly for motivational reasons, to overcome self-control problems - a process for which Read et al. coined the term motivational bracketing (see also Thaler and Shefrin 1981, Kahneman and Lovallo 1993).

As an illustration of how important motivational goal bracketing may be for everyday economic decisions, consider the study of New York City cab drivers' labor supply behavior by Camerer et al. (1997). The cab drivers appear to set a daily income goal for themselves, choose their working hours accordingly, and therefore display a negative wage elasticity ${ }^{2}$ Yet by taking it "one day at a time", they forgo gains in earnings and leisure that they could realize, for example, with a weekly target. Such a broader target would allow them to work fewer hours on days with low wages by compensating with more hours on days with high wages. The reason that cab drivers nevertheless set daily income targets is that narrow goals may be better at mitigating self-control problems than a broad goal, as Camerer et al. (1997, p.427) as well as Read et al. conjecture: "If [cab drivers] had, for example, picked a weekly target they might have been tempted to quit early on any given day, while assuring themselves that they could make up the deficiency later in the week" (Read et al. 1999, p.189).

Correspondingly, our model of goal bracketing is built around a self-control problem that arises from a present bias (e.g., Strotz 1955, Phelps and Pollak 1968, Ainslie and Haslam 1992, Laibson 1997, O’Donoghue and Rabin 1999). For instance, an individual may judge that going for morning runs is in his long-run interest. But come the start of a day, the distant health benefits suddenly do not seem worth the effort. The preference reversal occurs because the costs become more salient when they are immediate and loom larger than the gains, which only accrue in the future.

Personal goals play an important role in helping to overcome such motivational problems.

\footnotetext{
${ }^{1}$ The terms go back to Read et al. 1999. The phenomenon is also referred to as narrow framing (Kahneman and Lovallo 1993), or mental accounting (Thaler 1980, 1985, 1990, 1999).

${ }^{2}$ Camerer et al. (1997) triggered a lively debate about the estimation of wage elasticities of labor supply (see Goette et al. 2004; Farber 2005, 2008; Fehr and Götte 2007; Crawford and Meng 2008). Particularly relevant for our purposes is the link between loss aversion and effort elasticities suggested by Fehr and Götte's (2007) field experiment (see Footnote 6).
} 
Bandura, for example, writes that "the regulation of motivation by goal setting is a remarkably robust phenomenon" (p.xii of his foreword to Locke and Latham 1990a). Goals serve as reference points against which actual task outcomes are measured, and people display loss aversion regarding goal achievement ${ }^{3}$ Falling short of a goal hence causes a psychological loss that weighs more heavily than the gain from achieving the goal. A consequence is that a higher goal raises the motivation of a future self to work hard. Yet a higher goal also increases the chances of falling short of the performance standard and thereby suffering a loss. So goals are painful self-disciplining devices; and this limits their attraction for selfregulation (see also Koch and Nafziger 2008). The key question we address is how people use goals when they face multiple tasks. Does an individual prefer to set narrow goals (i.e., to measure each task outcome against a separate performance standard) or a broad goal (i.e., to evaluate the combined task outcomes against a global performance standard)? Our model sheds light on the puzzle why people often bracket narrowly by making clearer the trade-offs involved, and yields conditions under which narrow bracketing is indeed optimal.

Our analysis starts by looking at the case where an individual works sequentially on two independent tasks, but does not learn about the outcome of the first task before deciding how much effort to put into the second task (the no-information scenario). We then turn to the case where the individual receives intermediate information (the information scenario). Intuitively, in the no-information scenario, a broad goal seems appealing because it pools outcomes across tasks and thus provides a partial hedge against the risk of falling short of the goal despite best efforts: a high outcome in one task can compensate for a low outcome in the other task. In contrast, with narrow goals the individual suffers a psychological loss in a task as soon as the respective task outcome is low. Due to this risk-pooling effect, the expected psychological cost of using a broad goal is lower than that for corresponding narrow goals.

The possibility of compensating for low performance in one task with high performance in the other task however also makes it more attractive to "lean back": if the individual shirks in one of the tasks, he can still achieve the broad goal and avoid a psychological loss. But the

\footnotetext{
${ }^{3}$ Summarizing decades of psychology research on goals, Locke and Latham write that "goals serve as the inflection point or reference standard for satisfaction versus dissatisfaction [...] For any given trial, exceeding the goal provides increasing satisfaction as the positive discrepancy grows, and not reaching the goal creates increasing dissatisfaction as the negative discrepancy grows" (Locke and Latham 2002, p.709-710). For an extensive survey see Locke and Latham (1990a). Heath, Larrick, and Wu (1999) note the similarity to the value function in Kahneman and Tversky's (1979) Prospect Theory, and present evidence supporting the view that goals work in conjunction with loss aversion. Using a controlled lab experiment to manipulate subjects' reference points, Abeler et al. (2009) observe that higher reference levels induce higher effort.
} 
fear of facing such a loss when shirking is where the incentive effect of a goal stems from 4 So a broad goal provides lower motivation for working hard in both tasks than corresponding narrow goals. What our model shows, however, is that the leaning-back effect alone is not sufficient for narrow goals to be optimal: there still are cases where the risk-pooling effect dominates, so that a broad goal performs better than narrow goals.

An additional effect arises if the individual receives intermediate information between the tasks - a setting that seems particularly relevant for many applications. For instance, the two different tasks may correspond to two working days of a cab driver in Camerer et al. (1997), where a driver knows what he earned on the previous day.

Again, a broad goal allows for low performance in one task to be offset by high performance in the other task, giving rise to the leaning-back effect. But, because the individual can observe the outcome of the first task before working on the second task, a second effect arises that further undermines the motivating force of a broad goal. If the individual observes that he was successful in the first task and has already achieved his goal, he will "rest on his laurels" and put in low effort in the second task. In contrast, if he observes a failure in the first task, he will work hard in the second task to still meet the goal. This asymmetric response, in turn, exacerbates the temptation to shirk in the first task. The reason is that the individual wants his future self to work hard and not to rest on his laurels. But hard work today, in addition to being painful, makes it more likely that the future self will rest on his laurels; so the individual is tempted not to give his best today. To overcome this temptation, the broad goal has to be much higher than what would be needed if the individual received no intermediate information. As we show, the resting-on-your-laurels effect and its adverse impact on first-period incentives make the broad goal perform worse than narrow goals: in the information scenario, narrow bracketing is always optimal.

Overall, our model helps clarify the driving forces for narrow goal bracketing. The leaningback effect for example captures what Camerer et al. (1997, p.427) might have had in mind in their discussion of why cab drivers set a daily income target: "A weekly or monthly target [instead of a daily one] would leave open the temptation to make up for today's shortfall tomorrow, or next week, and so on". While intuitively appealing as an explanation for narrow goals, our analysis shows that this effect on its own is not necessarily enough to overcome the disadvantages of narrow bracketing. Rather, our model suggests that intermediate information between the tasks, and the resulting resting-on-your-laurels effect and its adverse impact on first-period incentives, play a crucial role in explaining many of the instances of narrow goal bracketing that we observe.

The paper is organized as follows. Next, we discuss the related literature. Section 2 then

\footnotetext{
${ }^{4}$ In line with this, Heath, Larrick, and $\mathrm{Wu}$ (1999) observe that workers are twice as willing to provide effort to just meet a given goal than they are willing to work toward surpassing the goal.
} 
introduces our model of goal setting in a multiple-task environment, which is based on the single-task model in Koch and Nafziger (2008). To obtain closed-form solutions we simplify that model by using a binary variable to describe task outcomes. While this simplification makes the model tractable, none of its essential properties are lost, as we discuss in Section 3. This section also prepares the analysis of the no-information and information scenarios, which follow in Sections 4 and 5 , respectively. Section 6 concludes the paper.

\section{Related Literature}

Our paper contributes to three literature strands. First, the research on goals, carried out mainly by psychologists (for an overview see e.g. Locke and Latham 1990a). Most of these studies investigate the effect of given goals (e.g., exogenously assigned by an experimenter) on incentives and performance in various tasks.5 We analyze how individuals choose and design goals for themselves, thereby filling this gap and contributing to the small economics literature on goal choice (Falk and Knell 2004, Koch and Nafziger 2008, and in parallel and independent work to our papers, Suvorov and van de Ven 2008 and Hsiaw 2009a, 2009b). Our multiple-task model of goal setting is based on the single-task framework in Koch and Nafziger (2008), which is complementary to the single-task models by Suvorov and van de Ven (2008) and Hsiaw (2009a). They take a different approach and model goals as selffulfilling rational expectations. Most closely related to our question is Hsiaw (2009b), who extends her single-task model to study goal bracketing with two sequential continuous-time optimal stopping problems. In contrast to our model, costs and benefits from a project accrue at the same time, and it is the tension between the option value of waiting versus stopping today at a known project value that gives rise to a self-control problem. Goals help counter the tendency of the present-biased individual to stop projects too early. So the intuition is quite different from the one developed in our model. First, narrow goals allow better regulation of stopping times relative to a broad goal, but cause disutility from frequent goal evaluation. Second, as Hsiaw assumes that the agent receives no intermediate information between the periods, the resting-on-your-laurels effect that arises in our model plays no role in her results.

Falk and Knell's (2004) social comparison model looks at the role of self-enhancement (people use comparisons with others to make themselves feel better) and self-improvement (people use comparisons with others to improve their own performance) for goal choice. We highlight

\footnotetext{
${ }^{5}$ For example, Fuhrmann and Kuhl (1998, p.653) note: "Goals are typically considered to be 'just there' and the interest of research mostly remains restricted to the process of how the organism manages to reach goals. We believe that the process by which goals are formed and become an object of self-regulation deserves much more attention in self-regulation research." Similarly, Bargh (1990), Carver and Scheier (1999), and Oettingen, Pak, and Schnetter (2001) mention that little is known about why and how people set goals for themselves.
} 
another important motivation for goal setting: the regulation of own behavior when people face self-control problems.

Second, our paper relates to the choice bracketing literature, that goes back to Tversky and Kahneman (1981), Simonson (1990) and Herrnstein and Prelec (1991) (for an overview see e.g. Read et al. 1999; Thaler 1999). Narrow bracketing is observed in a wide range of settings, such as consumption decisions (Cicchetti and Dubin 1994, Heath and Soll 1996) or lottery choices (Tversky and Kahneman 1981, Thaler, Tversky, Kahneman, and Schwartz 1997, Rabin and Weizsäcker 2009).

In conjunction with loss-aversion, a narrowly defined reference point can account for a range of puzzles and "wrong" decisions, such as the equity premium puzzle (Benartzi and Thaler 1995, Gneezy and Potters 1997), low stock market participation (Barberis 2001), choice errors (Thaler 1999), asymmetric price elasticities (Hardie, Johnson, and Fader 1993), the fact that investors hold on to "loosing" stocks too long (Odean 1998), and why workers work fewer hours/provide less effort on high-wage days - as e.g., the cabbies in Camerer et al.'s (1997) study, or the bicycle messengers in Fehr and Götte (2007) 6 The puzzle however is that broad bracketing would (all else equal) lead to better outcomes than narrow bracketing.

Third, our paper contributes to the theoretical literature that deals with the question how present-biased individuals cope with self-control problems (for an overview see e.g. Brocas, Carrillo, and Dewatripont 2004). Much of this literature focuses on the role of external commitment technologies for achieving pre-commitment (Elster 2000). Only a few contributions deal with intra-personal strategies, as our paper. Similar to our approach, Benhabib and Bisin (2005) and Herweg and Müller (2008) assume the presence of an internal commitment device and ask how an individual can use it to regulate behavior. Koch and Nafziger (2009) model the use of self-rewards. In a model where an individual has imperfect recall about past motives, Bénabou and Tirole (2004) can explain why internal commitment devices actually work.

\section{The model}

Overview. An individual needs to decide how much effort to put into two tasks that occur in sequence. In the no-information scenario, the individual does not learn about the

\footnotetext{
${ }^{6}$ Camerer et al. (1997) observe that narrow bracketing and loss aversion relative to a reference point seem to go hand in hand. Fehr and Götte's (2007) field experiment is in line with a link between loss aversion and narrow income targets. In response to an exogenous and transitory 25 percent increase in the commission rate, bicycle messengers with higher loss aversion (elicited using lottery choices) displayed more negative effort elasticities. Those with no loss aversion did not have a significantly negative elasticity.
} 
outcome of the first task before working on the second task. In the information scenario, the individual receives intermediate information before working on the next task. The cost of effort for a task is immediate, whereas the task outcome (and the related utility) realize only later. The individual has a present bias, and this bias creates an intra-personal conflict of interest: before the individual faces the tasks he thinks that working hard in both tasks is optimal; but once he makes the actual effort choices, all else equal, he will shirk. In anticipation of this self-control problem, the individual sets goals that serve as reference points for the future outcomes.

The tasks. The individual faces two symmetric tasks $i \in\{1,2\}$. Each task leads to an outcome $y_{i} \in\{\underline{y}, \bar{y}\}$, where $\bar{y}>\underline{y}$. We normalize $\underline{y} \equiv 0$. For each task the individual can choose whether to work hard $\left(\bar{e}_{i}=1\right)$ or shirk $\left(\underline{e}_{i}=0\right)$. Effort causes an instantaneous utility $\operatorname{cost} c \cdot e_{i}$. The outcome depends on both effort and luck: effort in task $i$ leads to a successful outcome $y_{i}=\bar{y}$ with probability $p \cdot e_{i}$, where $p \in(0,1)$. The outcome realization for each task is independent of that in the other task.

Goal setting. Before working on the tasks, the individual can choose a goal which then becomes anchored in his head as a standard for the future outcome to be achieved: he can either specify a separate reference standard for each task $i \in\{1,2\}$, i.e., a narrow goal $a_{n_{i}} \in[0, \infty)$, or a global reference standard for the sum of the outcomes in both tasks, i.e., a broad goal $a_{b} \in[0, \infty)$, or no goal (which corresponds to a reference standard that will be met for sure, i.e., $a_{n_{i}}=0$ or $\left.a_{b}=0\right)$.7 The assumption that an individual has the capacity to set goals for himself that remain meaningful over time is grounded in the psychology literature. For example, Gollwitzer (1999) writes: "By forming goal intentions, people translate their noncommittal desires into binding goals. The consequence of having formed a goal intention is a sense of commitment that obligates the individual to realize the goal."

Timing and utilities. Figure 1 summarizes the timing. At date 0, the individual chooses the goal bracket and level(s): a broad goal $\left(a_{b}\right)$, two narrow goals $\left(a_{n 1}, a_{n 2}\right)$, or no goal. No payoff-relevant events occur, so $u_{0}=0$.

Date-1 utility reflects the immediate cost of effort exerted in the first task: $u_{1}=-c\left(e_{1}\right)$. At date 2 , the individual works on the second task, so $u_{2}=-c\left(e_{2}\right)$. In the information scenario, he observes the outcome of task 1 before he provides effort at date 2 . In the no-information

\footnotetext{
${ }^{7}$ The lower bound on the goal level captures the idea that goals have to be "realistic" (e.g., Locke and Latham 1990b): the individual cannot make himself infinitely happy by setting the goal "I want to achieve $-\infty$ points in the exam" even though the lowest possible outcome is zero points (as explained below, the lower the goal, the better the individual feels about a given level of performance). Imposing a "realistic" upper bound would not change any of our results: as we show, a narrow goal greater than $\bar{y}$, or a broad goal greater than $2 \bar{y}$, has no motivational power.
} 


\begin{tabular}{|c|c|c|c|}
\hline date 0 & date 1 & date 2 & date 3 \\
\hline 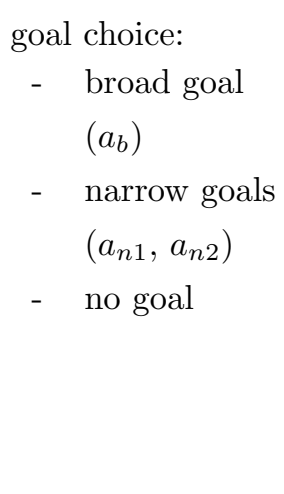 & $\begin{array}{l}\text { effort choice } \\
\text { for task } 1\left(e_{1}\right)\end{array}$ & $\begin{array}{ll}\text { - } & \text { effort choice } \\
& \text { for task } 2\left(e_{2}\right) \\
\text { - } & \text { info scenario: } \\
& \text { outcome of } \\
& \text { task } 1 \text { observed }\end{array}$ & 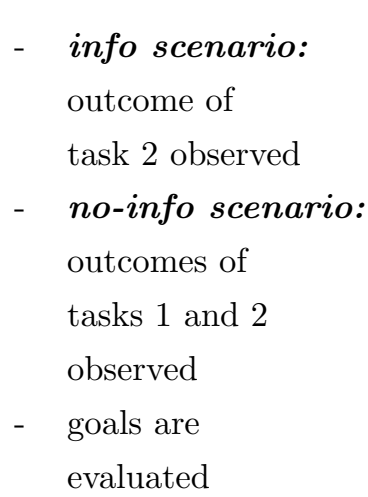 \\
\hline
\end{tabular}

Figure 1: Timing

scenario, he does not observe it: 8

At date 3, the individual experiences utility related to the realized task outcomes and the goal(s). There is extensive psychological evidence that people experience a loss if they fall short of a goal and a gain if they exceed it. Losses loom larger than gains of equal size. For example, Bandura (1989, p.1180) summarizes that "people seek self-satisfactions from fulfilling valued goals" and experience "discontent with substandard performances" (see also Section 1). We capture this with a value function in the spirit of Kahneman and Tversky (1979): depending on the difference between the outcome realization $y$ and the goal $a$, the individual experiences a gain $\mu^{+}(y-a)$ from satisfying the goal if $y \geq a$, and a loss $\mu^{-}(a-y)$ from falling short of the goal if $y<a 9^{9}$ As in many applications of Kahneman and Tversky's (1979) gain-loss utility framework, we assume for tractability that the individual exhibits linear loss aversion: $\mu^{+}(y-a)=\max \{y-a, 0\}$ and $\mu^{-}(y-a)=\mu \cdot \max \{a-y, 0\}$, with $\mu>1$.

With narrow goals $a_{n_{i}}$, gain-loss utility relates to individual task performance $y_{i}, i=1,2$ :

$$
u_{3}=\sum_{i=1}^{2}\left(\max \left\{y_{i}-a_{n_{i}}, 0\right\}-\mu \max \left\{a_{n_{i}}-y_{i}, 0\right\}\right) \text {. }
$$

And with a broad goal $a_{b}$, the overall performance $y_{1}+y_{2}$ is measured against the goal:

$$
u_{3}=\max \left\{\left(y_{1}+y_{2}\right)-a_{b}, 0\right\}-\mu \max \left\{a_{b}-\left(y_{1}+y_{2}\right), 0\right\} \text {. }
$$

\footnotetext{
${ }^{8}$ The no-information scenario yields the same results as a scenario where the individual works simultaneously on both tasks, as we show in Appendix B

${ }^{9}$ In a somewhat different context, Köszegi and Rabin (2006) refer to such a gain-loss utility function as the individual's "psychological utility", which they distinguish from an outcome-based consumption utility component. Making such a distinction, by adding a consumption utility component (say, $v(y)=y$ ), would not change our qualitative results (but add notational clutter). With $v(\bar{y})>v(\underline{y}) \geq 0$, a high outcome is more valuable relative to our setting. So the parameter range where a conflict of interest between self 0 and self 1 arises (Assumption 1) becomes smaller, but is still non-degenerate. Moreover, self 0 is willing to specify a "painful" goal for a larger range of parameter values.
} 
In the absence of a goal, simply set $a_{b}=0$ (or $a_{n i}=0$ ).

Our setup is a simplified version of the single-task goal setting model in Koch and Nafziger (2008). There, both the goal level and the outcome have the same continuous support, i.e., a goal always corresponds to a possible outcome level. The key property however is that varying the goal level shifts the expected psychological gain from exceeding the goal relative to the expected psychological loss from falling short of it. Our setting preserves this essential feature, while making the model sufficiently tractable for analyzing multi-task problems (see Section 3).

Present bias. The individual has time-inconsistent preferences in the sense of Strotz (1955). A present bias causes current payoffs to be more salient than future payoffs. Following the literature (e.g., Phelps and Pollak 1968, Laibson 1997, O’Donoghue and Rabin 1999), we model this using $(\beta, \delta)$-preferences. The first parameter, $\delta$, corresponds to the standard exponential discount factor (for simplicity, we assume $\delta=1$ ). The second parameter, $\beta \in$ $[0,1)$, captures the extent of the present bias, and is the parameter of interest in our model. The utility of the individual at date $t \in\{0,1,2,3\}$ is given by:

$$
U_{t}=u_{t}+\beta\left[\sum_{\tau=t+1}^{3} u_{\tau}\right] \text {, }
$$

where $u_{t}$ is the instantaneous utility at date $t$. For instance, the date- 0 incarnation of the individual (self 0 ) weighs future utilities $u_{1}, u_{2}$ and $u_{3}$ equally; but the date- 1 incarnation of the individual (self 1 ) puts a larger relative weight on $u_{1}$ by discounting $u_{2}$ and $u_{3}$ with $\beta<1$, reflecting his present bias. We assume that self 0 knows about the present-biased preferences of his future selves, i.e. is sophisticated in the sense of O'Donoghue and Rabin (1999). Without this knowledge, self-regulation clearly would make no sense.

Self-control problem. To make the problem interesting, we assume that a conflict of interest between self 0 and later-date selves arises in the absence of a positive goal level. For self 0 the choice of effort still lies in the future, and he therefore weighs equally the effort costs and the future benefits related to each task outcome. High effort in a task is therefore optimal from the date- 0 perspective if the expected utility it yields $(\beta\{p \bar{y}-c\})$ exceeds that from low effort $(\beta \underline{y}=0)$. That is, self 0 wants his future self to work hard in the tasks if and only if

$$
\beta\{p \bar{y}-c\} \geq 0 .
$$

Only in the case with no present bias $(\beta=1$ ) does self 1 (or self 2 ) choose exactly as self 0 would. But because $\beta<1$, the individual overemphasizes immediate costs relative to the distant benefits. As a result, self 1 (self 2) may prefer to shirk, while self 0 wants his later incarnation(s) to work hard. To see this formally, note that in the absence of a goal it is 
optimal to provide low effort from the perspective of self 1 (self 2 ) if and only if

$$
\beta p \bar{y}-c<0
$$

Thus, whenever both (2) and (3) hold, the individual has a self-control problem. The following assumption summarizes this.

Assumption 1 (Self-control problem) Self 0 prefers high effort in each task, but in the absence of a goal, the self making the effort decision on a task will choose low effort, i.e., $p \bar{y} \geq c$ and

$$
\beta_{s c} \equiv \frac{c}{p \bar{y}}>\beta
$$

\section{The basics of goal setting (a single task)}

To prepare for our main analysis, we first look at how an individual sets a goal for himself if there is only a single task to be completed. When designing his task goal, self 0 anticipates what it takes to motivate self 1 to provide effort. We therefore solve by backward induction: starting with the effort choice at date 1, we ask how self 1 responds to a given goal. Then we determine what is the optimal goal from the perspective of self 0 .

\subsection{The incentive effect of a given goal}

For a given goal related to the task, self 1 provides high effort if and only if the expected utility of self 1 if he works hard exceeds that if he shirks: $U_{1}(a ; \bar{e}) \geq U_{1}(a ; \underline{e})$. For $a \leq \bar{y}$ this "incentive constraint" is given by (see Appendix A.1):

$$
a \beta(\mu-1)[\operatorname{Pr}(\operatorname{loss} \mid \underline{e})-\operatorname{Pr}(\operatorname{loss} \mid \bar{e})] \geq c-\beta p \bar{y}
$$

where $\operatorname{Pr}(\operatorname{loss} \mid e)$ gives the probability that the individual falls short of the goal (thereby suffering a psychological loss) when providing effort level $e$. The incentive constraint shows how and why a goal motivates an individual to work hard. Think of studying for an exam. Cramming yields self 1 net-utility $\beta p \bar{y}-c$, which however is negative: the benefit from an expected good grade does not compensate for the cost of studying hard, because of the individual's present bias (Assumption 1). Hence, self 1 would refrain from working hard in the absence of a goal. Motivating himself to study for an exam however is easier if he has a target grade, as he then fears suffering a loss from not reaching his goal. If self 1 shirks, the probability of failing the goal is larger (it is equal to 1) than if he works hard (the probability then is $1-p)$ - so the left-hand side of the incentive constraint is positive. Hence, with an appropriately chosen goal, the loss avoided by exerting effort offsets the net cost from hard work. More precisely, the goal level, where (5) just holds, is given by

$$
\hat{a}=\frac{c-\beta p \bar{y}}{\beta p(\mu-1)} .
$$


The more severe the present bias (i.e., the lower $\beta$ ), the more difficult it is to incentivize self 1 and thus the higher the required goal level $\hat{a}$. If however the present bias is so strong that $\hat{a}$ exceeds $\bar{y}$, self-regulation becomes impossible. The reason is that in this case the incentive constraint (5) needs to be modified: with such a goal the individual experiences a loss no matter whether he works hard or shirks. As loss aversion no longer kicks in, the goal simply cancels out from the incentive constraint 10 In sum, self-regulation with a goal is feasible if and only if $\hat{a} \leq \bar{y}$, which is equivalent to $\frac{1}{\mu} \beta_{s c} \leq \beta$ ( $\beta_{s c}$ is defined in Assumption 1 ).

\subsection{What goal does self 0 choose?}

Holding the effort level $e$ fixed, a higher goal increases the chance of falling short of the aspired outcome $a$. But this matters more than the chance of exceeding $a$, because losses loom larger than gains of equal size. So a higher goal level is painful, because it reduces the utility self 0 expects from a given effort level $e: \frac{d}{d a} U_{0}(a ; e)<0$.

This shows clearly that the only purpose of setting $a>0$ is to discipline self 1 to put in more effort than he would exert in the absence of a positive goal. Thus, the choice of self 0 is a relatively simple one: either avoid the pain from an ambitious goal by abstaining from goal setting, and live with low effort; or pick the goal level that just suffices to motivate self 1 to work hard (if this is feasible). In other words, self 0 will specify a positive goal if his expected utility with goal $\hat{a}$ and high effort in the future exceeds the utility from $a=0$ and low effort in the future: $U_{0}(\hat{a} ; \bar{e}) \geq U_{0}(0 ; \underline{e})=0$. Lemma 1 below characterizes this in terms of $\beta$ (it corresponds to Proposition 1 in Koch and Nafziger 2008).

\section{Risk pooling vs leaning back (the no-information scenario)}

We start our analysis of the two-task setting with the no-information scenario, where the individual does not learn about the first task outcome before working on the second task. For example, think of studying for two exams in unrelated subjects, that take place in close sequence. Before even taking the first exam, you need to already study for the second exam. So all you know is how much (or little) effort you put into preparing for the first exam.

\subsection{Self-regulation with narrow goals}

If the individual sets narrow goals, he will evaluate task outcomes separately. (Did I reach the target grade in the first exam? Did I in the second?) Given the symmetry of tasks, the problem for each task hence mirrors the one in the single-task setting above. The minimum

\footnotetext{
${ }^{10}-\beta \mu\{p(a-\bar{y})+(1-p) a\}-c \geq-\beta \mu a . \Leftrightarrow \beta p \bar{y} \geq c$, which does not hold because of Assumption 1
} 
narrow goal level required to motivate self 1 to work hard on task $i$ is just the one from Equation (6), i.e.,

$$
\hat{a}_{n}=\frac{c-\beta p \bar{y}}{\beta p(\mu-1)} .
$$

The following result provides the conditions under which self-regulation with narrow goals is more attractive than no goal (i.e., when $\left.U_{0}\left(\hat{a}_{n}, \hat{a}_{n} ; \bar{e}_{1}, \bar{e}_{2}\right) \geq U_{0}\left(0,0 ; \underline{e}_{1}, \underline{e}_{2}\right)=0\right)$.

\section{Lemma 1}

(i) Self-regulation with narrow goals is feasible if and only if $\frac{1}{\mu} \beta_{s c} \leq \beta$.

(ii) There exists a cutoff $\beta_{n}$, satisfying $\frac{1}{\mu} \beta_{s c}<\beta_{n}<\beta_{s c}$, such that for $\beta \in\left[\beta_{n}, \beta_{\text {sc }}\right)$ self 0 sets the narrow goal $\hat{a}_{n}$ from (4) for each task rather than no goal, and self 1 and 2 provide high effort.

In other words, there exists a range for the present bias parameter $\beta$, for which self 0 would find it worthwhile to engage in self-regulation with adequately chosen task-specific goals $\left(a_{n i}=\hat{a}_{n}\right)$. If there was no intra-personal conflict of interest - i.e., if $\beta$ exceeded $\beta_{s c}-$ no goal would be needed: self 1 would exert high effort anyway. In contrast, if $\beta$ falls in between $\frac{1}{\mu} \beta_{s c}$ and $\beta_{n}$, it would be feasible to overcome the self-control problem with narrow goals, yet the required goal levels are too painful for self 0 . So he rather gives up on self-regulation. If the self-control problem is very severe, $\beta<\frac{1}{\mu} \beta_{s c}$, no feasible narrow goal can help overcome it (but by the previous argument, it would be too painful to do so anyhow).

\subsection{Self-regulation with a broad goal}

The alternative to narrow task-specific goals is to set a broad goal related to the overall outcome from both tasks (e.g., reach some average grade score in the upcoming exams). One needs to distinguish between two cases. Is an "easy" broad goal $a_{b} \leq \bar{y}$, that can be achieved with one task outcome alone, enough to motivate self 1 and 2? Or does the goal have to be more ambitious, i.e., $\bar{y}<a_{b} \leq 2 \bar{y}$ (a "difficult" broad goal)? The difficult goal is more painful, and therefore only makes sense if an easy broad goal does not do the job.

When does an easy broad goal make sense. ${ }^{11}$ Because the individual evaluates the outcomes of the two tasks jointly, the (previous or expected future) effort choice of the other self influences the incentives of the current self. So we have to consider two cases: does the other self work hard, or does he shirk? If there will be shirking in one task, say by self 1 , the broad goal necessary to motivate self 2 just equals the narrow goal for that task - i.e., $a_{b}=\hat{a}_{n}$ from Equation (7). Yet if high effort in this task is worth the cost of the goal, then effort in the other task is also worth it. So in this case, narrow goals $\left(\hat{a}_{n}, \hat{a}_{n}\right)$ dominate.

\footnotetext{
${ }^{11}$ Formal details for the following arguments are given in Appendix A.3
} 
Now consider what it takes to get both self 1 and 2 to put in effort. If self 2 knows that his previous self worked hard at date 1 , a broad goal $a_{b} \leq \bar{y}$ provides incentives for him to work hard in the second task if:

$$
a_{b} \beta(\mu-1)\left[\operatorname{Pr}\left(\operatorname{loss} \mid \underline{e}_{2}, \bar{e}_{1}\right)-\operatorname{Pr}\left(\operatorname{loss} \mid \bar{e}_{2}, \bar{e}_{1}\right)\right] \geq c-\beta p \bar{y} .
$$

The interpretation is similar to that of the incentive constraint (5) for the single-task setting/narrow goals: while shirking saves $c-\beta p \bar{y}$ - the net-utility cost of effort of self 2 in the task (note that the effort cost of self 1 is already sunk) - it exposes the individual to the risk of falling short of the goal. Shirking now however does not for sure lead to a loss (as under narrow goals), but only with probability $1-p$ : a high outcome in the first task, where self 1 put in effort already, can compensate for the low outcome that shirking causes in the second task. By working hard, self 2 can reduce the probability of a loss to $(1-p)^{2}$. So $\operatorname{Pr}\left(\operatorname{loss} \mid \underline{e}_{2}, \bar{e}_{1}\right)-\operatorname{Pr}\left(\operatorname{loss} \mid \bar{e}_{2}, \bar{e}_{1}\right)=p(1-p)$, and the broad goal necessary to motivate self 2 is given by:

$$
\hat{a}_{b}=\frac{c-\beta p \bar{y}}{\beta p(1-p)(\mu-1)} .
$$

This goal also motivates self 1 to work hard if he expects self 2 to put in effort. The reason is that the incentive constraint of self 1 simply reduces to the one in (8): the anticipated effort cost of self 2 appears on both sides of the incentive constraint, and thus cancels out without influencing the decision of self 1 whether to work hard or shirk.

The following result provides the condition under which the "easy" broad goal $\hat{a}_{b} \leq \bar{y}$ is better than abstaining from setting a positive goal altogether (i.e., when $U_{0}\left(\hat{a}_{b} ; \bar{e}_{1}, \bar{e}_{2}\right) \geq$ $\left.U_{0}\left(0 ; \underline{e}_{1}, \underline{e}_{2}\right)\right)$.

\section{Lemma 2}

(i) Self-regulation for both tasks with an "easy" broad goal $\left(\bar{y} \geq a_{b}>0\right)$ is feasible if and only if $\frac{1}{(1-p) \mu+p} \beta_{s c} \leq \beta$.

(ii) There exists a cutoff $\beta_{b}$ satisfying $\frac{1}{(1-p) \mu+p} \beta_{s c}<\beta_{b}<\beta_{s c}$, such that for $\beta \in\left[\beta_{b}, \beta_{s c}\right)$ self 0 sets the "easy" broad goal $\hat{a}_{b}$ from (9) rather than no goal, and self 1 and 2 provide high effort.

Similar to the case of narrow goals, even if a broad goal that would help overcome the selfcontrol problem is feasible, this does not mean that the individual is willing to use it. For $\frac{1}{(1-p) \mu+p} \beta_{s c}<\beta<\beta_{b}$, it is better to set no goal than to assure effort at the cost of a painful broad goal.

This, as we now argue, also implies that a difficult broad goal $\left(\bar{y}<a_{b} \leq 2 \bar{y}\right)$ can never be optimal. Self 0 will consider such a goal only if it is not possible to solve the motivation problem with an easy broad goal. In the parameter range where this is true, $\beta<\frac{1}{(1-p) \mu+p} \beta_{s c}$, the benefit of higher effort however does not even outweigh the cost of setting an easy broad 
goal. So, a fortiori, a difficult broad goal would yield negative utility for self 0 . First, there is a larger loss of falling short of the goal, as it is larger (by construction) than any easy broad goal. Second, a high outcome in one task can no longer fully compensate for a low outcome in the other task, so the individual also suffers a loss more often than with an easy broad goal.

Lemma 3 Self 0 will never adopt a "difficult" broad goal $\left(\bar{y}<a_{b} \leq 2 \bar{y}\right)$.

As the easy broad goal $\hat{a}_{b}$ is the only candidate that can beat narrow goal bracketing, we will henceforth refer to the easy broad goal simply as the broad goal.

\subsection{Motivational bracketing: broad vs narrow goals}

Is broad or narrow goal bracketing better suited for self-regulation? To answer this question, suppose first that those goals that motivate the individual - be they broad or narrow dominate setting no goal (i.e., $\beta \geq \max \left\{\beta_{n}, \beta_{b}\right\}$ ).

\subsubsection{The risk-pooling effect}

Broad bracketing would be superior if we were able to abstract from incentive considerations (say, because self 1 always works hard), and simply compared the utility of self 0 in the broad and narrow bracketing scenarios for the same goal level (say, $a=a_{b}=a_{n}$ ). Under both scenarios, the individual experiences disutility $2 c$ from working hard in the tasks, and looks forward to an expected utility flow from the task outcomes of $2 p \bar{y}$ in the future. In addition, he has to incur the psychological cost of goal setting. But that cost under broad bracketing is different from the one under narrow bracketing: there is a risk-pooling effect. Specifically, as the broad goal is lower than $\bar{y}$ (Lemma 3), a high outcome in one task can compensate for a low outcome in the other task. The individual therefore experiences a loss only if the outcomes in both tasks are low, so the expected loss is $(1-p)^{2} \mu a$. In contrast, narrow goals provide no scope for risk pooling: the individual experiences a loss as soon as the outcome is low in any of the two tasks. Hence, the overall probability of a loss increases from $(1-p)^{2}$ to $2(1-p)$. With the respective complementary probabilities, the individual achieves his goal(s), and experiences a gain (i.e., the goal then is not weighed by $\mu$ ). Plugging everything in, we obtain

$$
\text { the psychological cost of a broad goal } a_{b}=a: \underbrace{\left[2 p-p^{2}+(1-p)^{2} \mu\right]}_{\equiv[\text { broad }]} \times a,
$$

and

$$
\text { the psychological cost of narrow goals } a_{n 1}=a_{n 2}=a: \underbrace{2[p+(1-p) \mu]}_{\equiv[\text { narrow }]} \times a \text {. }
$$

As losses loom larger than gains $(\mu>1)$, the overall cost under a broad goal is lower than that under corresponding narrow goals: $[$ broad $]<[$ narrow $]$. 


\subsubsection{The leaning-back effect}

Yet the above comparison is incomplete, because it neglects the incentive side. The optimal broad goal $\left(\hat{a}_{b} \leq \bar{y}\right.$ by Lemma 3 ) provides a buffer against a loss also if the individual shirks in one of the tasks; and this buffer creates an incentive to lean back in one of the tasks.

To understand this leaning-back effect, take as given the goal level under the narrow and broad bracketing scenarios. Now ask where the individual has a greater motivation to work hard. If self 1 and 2 both exert effort, the probability of falling short of the broad goal is $(1-p)^{2}$. Shirking in a single task by one of the selves raises this probability, but only to $1-p$ : a high outcome in the other task, where effort is put in, can compensate for the low outcome that shirking will cause in the task at hand. In contrast, under a narrow goal, shirking in a single task leads to a loss with probability one. Effort lowers this probability to $1-p$ for each task. So the difference that hard work in both tasks makes relative to shirking in one task is smaller with the broad goal than with the corresponding narrow goals (a drop in the probability of a loss of $p(1-p)$ versus one of $p)$. As a result, the individual needs to set a more ambitious broad goal to motivate effort than the required goal level under narrow bracketing 12

Lemma 4 Motivating self 1 requires a larger goal level under broad bracketing than under narrow bracketing:

$$
\hat{a}_{b}=\frac{\hat{a}_{n}}{1-p}>\hat{a}_{n}
$$

\subsubsection{When is narrow bracketing optimal?}

What is the overall effect? Comparing the expected utility of self 0 from setting two narrow goals $\hat{a}_{n}$ with that from setting the broad goal $\hat{a}_{b}$, the next result shows that narrow bracketing can indeed be optimal.

Proposition 1 (No-information scenario) Suppose that setting some type of goal is optimal, i.e., $\beta \geq \min \left\{\beta_{n}, \beta_{b}\right\}$. Then the individual brackets goals narrowly rather than broadly if and only if

$$
p^{2}-(1-p)^{2} \mu \geq 0,
$$

or equivalently, if and only if $\beta_{b} \geq \beta_{n}$.

The formula shows that for large $p$ narrow bracketing is optimal, while for $p \leq 1 / 2$ the broad goal is for sure better ${ }^{13}$ A broad goal $\hat{a}_{b}$ allows to hedge against the risk of suffering

\footnotetext{
${ }^{12}$ The effects described here are robust to correlation in task outcomes. Unless tasks are perfectly positively correlated, the risk-pooling effect arises (i.e., broad goals have a lower psychological cost than narrow goals). And unless tasks are perfectly negatively correlated, the leaning-back effect arises.

${ }^{13}$ To see the latter, note that the broad goal is better than the narrow goals if it involves a lower psychological cost, i.e., if $\frac{\hat{a}_{n}}{1-p} \times[$ broad $] \leq 2 \hat{a}_{n} \times[$ narrow $]$. For $p \leq \frac{1}{2}$, we have that $\frac{\hat{a}_{n}}{1-p} \leq 2 \hat{a}_{n}$. And from $[10$ and (11) we know that [broad $]<[$ narrow $]$. So broad bracketing is for sure better if $p \leq 1 / 2$.
} 
a loss. While the direct impact of the risk-pooling effect on the utility of self 0 is positive, it decreases the motivational power of a given goal. The leaning-back effect dominates for a high success probability $p$. The reason is that the incentive power (the impact of effort in terms of lowering the probability of suffering a loss) increases with $p$ under narrow bracketing, whereas for a broad goal it is strongest at $p=1 / 2$.

\section{$5 \quad$ Resting on your laurels (the information scenario)}

So far we assumed that the individual does not receive intermediate information between the tasks. In many settings though, people work in tasks sequentially and receive information about task outcomes in between tasks. For instance, the cabbies from Camerer et al.'s (1997) study learn about their earnings on a given day before starting their next working day. A student taking a series of exams over the course of an academic year learns about how well he did in one exam before studying for the next exam. So we consider now the information scenario, where the individual gets to know the outcome of task 1 before providing effort at date 2 (see Figure 1 , 14

\subsection{Narrow goals are invariant to information}

For self-regulation with narrow goals it is irrelevant whether the individual receives intermediate information or not, because task outcomes are evaluated separately: a past success provides no excuse to slack off today, and a past failure also does not provide extra motivation to make up for it. So our results from Section 4.1 carry over.

\subsection{The resting-on-your-laurels effect under a broad goal}

Again we have to distinguish between an "easy" and a "difficult" broad goal. It turns out that a difficult broad goal $\left(\bar{y}<a_{b} \leq 2 \bar{y}\right)$ can never be optimal, essentially for the same reasons as in Section 4.2. We show this in Appendix A.9, and simply refer to an easy broad goal $\left(a_{b} \leq \bar{y}\right)$ as the broad goal in the following.

Consider first the incentives of self 2: What are his incentives to work hard if he observes a first-period failure? And what if he observes a first-period success? In the case of a firstperiod success, the risk-pooling effect of the broad goal undermines incentives: self 2 knows that he has already exceeded the goal and will not risk a loss even if he shirks on the second

\footnotetext{
${ }^{14}$ The choice bracketing literature suggests that people evaluate differently events that are spread over time, depending on whether they bracket narrowly or broadly (e.g., Read et al. 1999, Thaler 1999). Without changing our results, we could assume that under narrow bracketing the goal for the first task is evaluated at date 2 (instead of date 3): with narrow goals, psychological accounts can be settled as soon as a goal-related outcome realizes. A broad goal, in contrast, leaves the account open until the final goal-related outcome becomes known. That is, goal evaluation only takes place at date 3, after all goal-related events have realized.
} 
task. So the fear of a loss - which we know is needed to motivate self 2 to exert effort is gone. Hence, self 2 will "rest on his laurels" and shirk on the second task - even though effort would be optimal from the perspective of self 0 .

In contrast, if self 2 observes a first-period failure, he knows that he can achieve the broad goal by working hard on the next task. In this case, the incentive problem for self 2 mirrors the one under narrow bracketing: the focus is on the single task ahead, because the effort cost of self 1 is sunk and the first-period outcome cannot be influenced - no matter whether self 2 works hard or not. So to motivate self 2 to work hard (after a low first-task outcome) it takes a broad goal level of at least $\hat{a}_{n}$ from Equation (7).

But the asymmetric response of self 2 to the outcome of the first task changes the incentive constraint for self 1 as well. Self 1 anticipates correctly that self 2 will rest on his laurels if he succeeds today. While self 1 thinks that shirking today is the optimal thing to do in the absence of a sufficiently ambitious goal (on account of his present bias), he does prefer self 2 to work hard tomorrow rather than to shirk. And self 1 can, by shirking today, always push self 2 to work hard: the first task outcome then will for sure be low and hence self 2 will for sure work to make up for this - resulting in expected utility $\beta(p \bar{y}-c)>0$ for self 1. In contrast, if self 1 works hard he reduces the probability that self 2 will work hard to $1-p$ (the probability with which the first task outcome will be low). So as a result of the resting-on-your-laurels effect, the individual has lower incentives to work hard on the task at date 1 compared to a situation were the individual receives no intermediate information. It therefore is quite intuitive that the broad goal required to motivate self 1 in the information scenario is larger compared to the no-information scenario. This, in turn, means that it also is larger than the narrow goal $\hat{a}_{n}$ (which would suffice to motivate self 2 to work hard after a first-period failure). Specifically, the broad goal required is given by (see Appendix A.7):

$$
\hat{a}_{b}^{\text {info }}=\underbrace{\frac{\hat{a}_{n}}{1-p}}_{=\hat{a}_{b}}+\frac{p \bar{y}-c}{(1-p)(\mu-1)} .
$$

Note that the leaning-back effect described in Section 4.3 still kicks in: it shows up in the first component (which is the same as for the no-information scenario). In addition, the goal has to counter the resting-on-your-laurels effect, as captured by the second component. The following lemma summarizes our observations:

\section{Lemma 5}

(i) If the outcome on task 1 is high, no "easy" broad goal $\left(a_{b} \leq \bar{y}\right)$ can motivate self 2 to provide high effort on task 2.

(ii) If the outcome on task 1 is low, any broad goal that weakly exceeds $\hat{a}_{n}$ leads to high effort on task 2. 


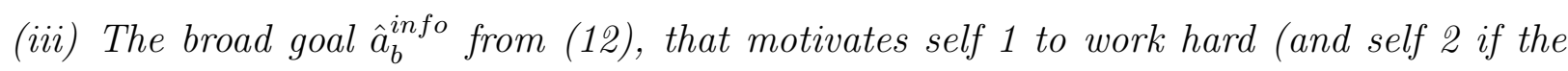
outcome on task 1 is low), is larger than the narrow goal $\hat{a}_{n}$ from (7), and larger than the broad goal in the no-information scenario $\hat{a}_{b}$ from (9).

In sum, the negative incentive effects of a broad goal are more pronounced if the individual receives intermediate information: the goal level increases; and the individual rests on his laurels after observing a high outcome in the first period (resulting in a utility loss of $\beta p(p \bar{y}-$ c) for self 0) 15 In contrast, the risk-pooling effect described in Section 4.3 is not affected by the intermediate information: the psychological cost of the broad goal still behaves as in (10). Overall, moving from the information to the no-information scenario decreases the utility of self 0 under broad bracketing, but leaves his utility under narrow bracketing unaffected. As a consequence, broad goals must perform relatively worse if the individual receives intermediate information than if he does not.

\subsection{Motivational bracketing: broad vs narrow goals}

Can a broad goal still be optimal? The answer is no:

Proposition 2 (Information scenario) It is never optimal for self 0 to motivate future selves with a broad goal. Narrow goals are optimal if and only if $\beta \geq \beta_{n}$.

To gain some intuition for the result, note that for relatively low values of $p$ - where the individual does not succeed often - the resting-on-your-laurels effect plays a minor role. However, for low values of $p$ it also becomes quite difficult in general to motivate future selves to work hard: the expected gains from effort do not appear much larger than the ones from shirking, precisely because the individual does not succeed often. That is, the broad goal needs to be very large and, consequently, very painful for self 0 . Goal setting thus is generally unattractive for low values of $p$, and self 0 will rather let self 1 shirk. Indeed, the proof of Proposition 2 shows that whenever the negative effects of broad bracketing are weak and it stands a chance to do better than narrow bracketing (for low values of $p$ ), the broad goal that motivates effort by self 1 yields negative utility.

Thus, with intermediate information on the first task outcome, self 0 will either specify two narrow goals or no goal. A broad goal is never optimal even though it provides a hedge against the risk of falling short of the goal. The risk-pooling effect in fact is what causes the resting-on-your-laurels problem, because of which the broad goal becomes unattractive for self-regulation.

\footnotetext{
${ }^{15}$ Of course, the individual does not have to fight against the consequences of the resting-on-your-laurels effect. A lower broad goal will lead to shirking on the first task, but $a_{b}=\hat{a}_{n}$ will still get self 2 to work hard on the second task. But for the same psychological cost related to the second task, setting two narrow goals $\hat{a}_{n}$ will motivate effort also on the first task. So narrow bracketing clearly dominates.
} 


\section{Conclusion}

An important reason why we often see people evaluating consequences of choices separately rather than jointly (i.e., bracket narrowly) is that this allows them to overcome self-control problems. This conjecture - advanced among others by Thaler and Shefrin (1981), Kahneman and Lovallo (1993), Camerer et al. (1997), and Read et al. (1999) - is the starting point of our paper. With our model of goal setting by a present-biased individual we provide a tractable framework for studying the motivational bracketing hypothesis, and thus help clarify what driving forces may determine whether or not narrow bracketing is optimal.

Goals serve as reference points that make substandard performance psychologically painful. And the fear of suffering a loss from falling short of a goal is what can provide the impetus for effort, that an individual with a present bias may otherwise lack. But because there is a risk of falling short of a goal even if the individual works hard, goal setting is costly. Bracketing broadly - i.e., evaluating jointly the performance in two tasks - reduces this risk through a risk-pooling effect, because high performance in one task can compensate for low performance in another task. However, the possibility of offsetting outcomes also makes it less painful to shirk in one of the tasks (the leaning-back effect). Furthermore, if the individual learns about the outcome of the first task before facing the next task, incentives for effort on the second task are lower following a good outcome than following a bad outcome (the restingon-your-laurels effect). The latter two effects do not arise if the individual sets narrow task goals.

Our analysis sheds light on the particular circumstances where an individual who brackets narrowly can achieve better outcomes than one who uses a broad bracket. Narrow goals are superior at regulating self-control problems whenever the incentive dampening effects of broad goals are severe - which is the case, in particular, when the individual learns about a task outcome before engaging in the next task. Our results thus offer one important piece to fill in and understand better the puzzle of narrow bracketing. 


\section{Appendix}

\section{A Proofs}

\section{A.1 Derivation of the incentive constraint (5)}

Written out, the incentive constraint for self 1 is:

$$
\beta\{p(\bar{y}-a)-(1-p) \mu a\}-c \geq-\beta \mu a .
$$

Working hard, the goal is surpassed with probability $p$ (resulting in a gain $\bar{y}-a$ ); and with probability $1-p$ the task outcome falls short of the goal (resulting in a loss $\mu a$ ). Shirking results in a substandard outcome with associated loss $\mu a$. Rewritten in terms of the respective probabilities of obtaining a gain or a loss $(\operatorname{Pr}($ gain $\mid \bar{e})=p, \operatorname{Pr}(\operatorname{loss} \mid \bar{e})=1-p$, $\operatorname{Pr}($ gain $\mid \underline{e})=0$, and $\operatorname{Pr}(\operatorname{loss} \mid \underline{e})=1)$, the incentive constraint becomes:

$$
\beta\{\operatorname{Pr}(\text { gain } \mid \bar{e})(\bar{y}-a)-\operatorname{Pr}(\operatorname{loss} \mid \bar{e}) \mu a\}-c \geq \beta\{\operatorname{Pr}(\text { gain } \mid \underline{e})(\bar{y}-a)-\operatorname{Pr}(\operatorname{loss} \mid \underline{e}) \mu a\} .
$$

Rearranging:

$$
\beta a[\{\operatorname{Pr}(\text { gain } \mid \bar{e})-\operatorname{Pr}(\operatorname{gain} \mid \underline{e})\}+\mu\{\operatorname{Pr}(\operatorname{loss} \mid \underline{e})-\operatorname{Pr}(\operatorname{loss} \mid \bar{e})\}] \geq c-\beta p \bar{y} .
$$

Using $\operatorname{Pr}($ gain $\mid e)=1-\operatorname{Pr}(\operatorname{loss} \mid e)$ yields (5).

\section{A.2 Proof of Lemma 1}

With narrow goals, the utility is separable across tasks. So we can consider each task on its own, using the single-task incentive constraint (5).

(i) To motivate self 1 (self 2 ), a narrow goal of at least $\hat{a}$ is required. And this goal has to be feasible, i.e., $\hat{a} \leq \bar{y} \Leftrightarrow \frac{1}{\mu} \beta_{s c} \leq \beta$ (using the definition of $\beta_{s c}$ in Assumption 1 ).

(ii) By Assumption 1, for the utility component of self 0 related to task $i=1,2\left(U_{0 i}\left(a_{n i} ; e\right)\right)$ we have $U_{0 i}(0 ; \bar{e})-U_{0 i}(0 ; \underline{e})>0$. Moreover, $U_{0 i}(\bar{y} ; \bar{e})-U_{0 i}(0 ; \underline{e})=\beta[-(1-p) \mu \bar{y}-c]<$ 0 . Note that $U_{0 i}(a ; \bar{e})-U_{0 i}(0 ; \underline{e})$ is a continuous and strictly decreasing function in $a$, because $\mu>1$ :

$$
\frac{\partial}{\partial a} U_{0 i}(a ; \bar{e})=-\beta[\mu-p(\mu-1)]<0 .
$$

Applying the intermediate value theorem, there exists a unique value $\tilde{a} \in(0, \bar{y})$ such that $U_{0 i}(\tilde{a} ; \bar{e})-U_{0 i}(0 ; \underline{e})=0$. This is the maximum narrow goal level that self 0 would ever choose to get a future self to exert high effort in a task.

As tasks are symmetric, consider without loss of generality the effort choice of self 1 in task 1 . The next argument shows that there exists a $\beta_{n} \in\left(\underline{\beta}, \beta_{s c}\right)$ such that the 
single-task incentive constraint (5) holds at $\tilde{a}$, where $\underline{\beta} \equiv \frac{1}{\mu} \beta_{s c}$. Because utility is separable across tasks, we can write the incentive constraint in terms of a function $\Phi$ that captures the utility difference related to effort by self 1 on task 1 , and that is indexed by the present bias parameter $\beta$ :

$$
\Phi(a, \beta) \equiv \underbrace{[\beta\{p(\bar{y}-a)-(1-p) \mu a\}-c]}_{=U_{1}(a ; \bar{e})}-\underbrace{[-\beta \mu a]}_{=U_{1}(a ; \underline{e})} .
$$

From Assumption 1 we know that for $a=0$ the incentive constraint binds at $\beta=\beta_{s c}$ : $\Phi\left(0, \beta_{s c}\right)=0$. Note that $\frac{\partial}{\partial a} \Phi(\cdot)>0$. So, $\Phi\left(\tilde{a}, \beta_{s c}\right)>0$. Similarly, $\Phi(\bar{y}, \underline{\beta})=0$, which implies that $\Phi(\tilde{a}, \underline{\beta})<0$. Using $\frac{\partial}{\partial \beta} \Phi>0$, by the intermediate value theorem, there exists a unique $\beta_{n} \in\left(\underline{\beta}, \beta_{s c}\right)$ such that $\Phi\left(\tilde{a}, \beta_{n}\right)=0$. Thus, $\beta_{n}$ is the minimum value of the present-bias parameter $\beta$ for which self 0 would be willing to set a narrow goal to incentivize self 1 . While the precise formula for $\beta_{n}$ will be of little importance for our analysis, we state it here for completeness:

$$
\beta_{n}=\frac{[(1-p) \mu+p] c}{p[\mu \bar{y}-(\mu-1) c]} .
$$

\section{A.3 Proof of Lemma 2}

i) The relevant "easy" broad goal is $\hat{a}_{b}$ from Equation (9).

For an easy broad goal level $a_{b} \leq \bar{y}$, consider the incentive constraint of self 2 after he observes that self 1 worked hard:

$$
\beta\left\{p^{2}\left(2 \bar{y}-a_{b}\right)+2 p(1-p)\left(\bar{y}-a_{b}\right)-(1-p)^{2} \mu a_{b}\right\}-c \geq \beta\left\{p\left(\bar{y}-a_{b}\right)-(1-p) \mu a_{b}\right\} .
$$

Rewritten in terms of the respective probabilities of obtaining a gain or a loss ${ }^{16}$ and rearranging, the incentive constraint becomes:

$a_{b}\left[\operatorname{Pr}\left(\right.\right.$ gain $\left.\mid \underline{e}_{2}, \bar{e}_{1}\right)-\operatorname{Pr}\left(\right.$ gain $\left.\left.\mid \bar{e}_{2}, \bar{e}_{1}\right)-\mu\left\{\operatorname{Pr}\left(\operatorname{loss} \mid \bar{e}_{2}, \bar{e}_{1}\right)-\operatorname{Pr}\left(\operatorname{loss} \mid \bar{e}_{2}, \bar{e}_{1}\right)\right\}\right] \geq c-\beta p \bar{y}$.

Using $\operatorname{Pr}\left(\right.$ gain $\left.\mid e_{2}, \bar{e}_{1}\right)=1-\operatorname{Pr}\left(\operatorname{loss} \mid e_{2}, \bar{e}_{1}\right)$ yields Equation (8). Solving for $a_{b}$ and using $\operatorname{Pr}\left(\operatorname{loss} \mid \underline{e}_{2}, \bar{e}_{1}\right)-\operatorname{Pr}\left(\operatorname{loss} \mid \bar{e}_{2}, \bar{e}_{1}\right)=p(1-p)$ yields $\hat{a}_{b}$ in Equation (9).

Now consider the incentive constraint for self 1 (given that he expects self 2 to work hard):

$\beta\left\{p^{2}\left(2 \bar{y}-a_{b}\right)+2 p(1-p)\left(\bar{y}-a_{b}\right)-(1-p)^{2} \mu a_{b}-c\right\}-c \geq \beta\left\{p\left(\bar{y}-a_{b}\right)-(1-p) \mu a_{b}-c\right\}$.

Note that $-\beta c$ (the effort cost of self 2 ) appears on both sided of the incentive constraint and cancels out. Hence, the incentive constraints (13) and 14 coincide, so the broad goal $\hat{a}_{b}$ given in Equation (9) also motivates self 1 .

${ }^{16} \operatorname{Pr}\left(\right.$ gain $\left.\mid \underline{e}_{2}, \bar{e}_{1}\right)=p, \operatorname{Pr}\left(\operatorname{loss} \mid \underline{e}_{2}, \bar{e}_{1}\right)=1-p, \operatorname{Pr}\left(\operatorname{gain} \mid \bar{e}_{2}, \bar{e}_{1}\right)=p^{2}+2 p(1-p)$, and $\operatorname{Pr}\left(\operatorname{loss} \mid \bar{e}_{2}, \bar{e}_{1}\right)=(1-p)^{2}$. 
Similarly, the incentive constraint of self 2 after he observes that self 1 shirked is:

$$
a_{b} \beta(\mu-1) \underbrace{\left[\operatorname{Pr}\left(\operatorname{loss} \mid \underline{e}_{2}, \underline{e}_{1}\right)-\operatorname{Pr}\left(\operatorname{loss} \mid \bar{e}_{2}, \underline{e}_{1}\right)\right]}_{1-(1-p)=p} \geq c-\beta p \bar{y} .
$$

Again this coincides with the incentive constraint for self 1, if self 1 expects self 2 to shirk. Note also that the incentive constraint (15) coincides with the singletask/narrow-goals incentive constraint (5), so it binds at $a_{b}=\hat{a}_{n}$. As $\hat{a}_{n}<\hat{a}_{b}$, self $t \in\{1,2\}$ will work hard under $\hat{a}_{b}$, even if the self responsible for the other task does not.

ii) Part (i) of Lemma 2 .

The upper bound on an "easy" broad goal, $a_{b} \leq \bar{y}$, implies that $\hat{a}_{b}$ is feasible if and only if

$$
c \leq \beta p \bar{y}[(1-p) \mu+p] \quad \Leftrightarrow \quad \frac{1}{(1-p) \mu+p} \beta_{s c} \leq \beta
$$

iii) Part (ii) of Lemma 2.

The proof of Part (ii) is analogous to that of Lemma 1 and therefore omitted. Again, the precise formula for the cutoff value is of little importance, but we state it here for completeness:

$$
\beta_{b}=\frac{\left[\mu(1-p)^{2}+p(2-p)\right] c}{p\left[\mu\left(\left(1-p^{2}\right) \mu+p^{2}\right) \bar{y}-2(\mu-1)(1-p) c\right]} .
$$

\section{A.4 Proof of Lemma 3}

See Section 4.2.

\section{A.5 Proof of Lemma 4}

Comparing the narrow goal $\hat{a}_{n}=\frac{c-\beta p \bar{y}}{\beta p(\mu-1)}$ with the broad goal $\hat{a}_{b}=\frac{c-\beta p \bar{y}}{\beta p(1-p)(\mu-1)}$, it is straightforward that $\hat{a}_{b}=\hat{a}_{n} /(1-p)$.

\section{A.6 Proof of Proposition 1}

For narrow goals the (normalized) expected utility of self 0 is:

$$
U_{0}\left(\hat{a}_{n}, \hat{a}_{n} ; \bar{e}_{1}, \bar{e}_{2}\right) / \beta=2(p \bar{y}-c)-\hat{a}_{n}[2 p+2(1-p) \mu] .
$$

For the broad goal it is:

$$
U_{0}\left(\hat{a}_{b} ; \bar{e}_{1}, \bar{e}_{2}\right) / \beta=2(p \bar{y}-c)-\hat{a}_{b}\left[2 p-p^{2}+(1-p)^{2} \mu\right] .
$$


So the expected utility of self 0 under narrow bracketing is larger than the one from broad bracketing if and only if the expected cost of goal setting with narrow bracketing, $\hat{a}_{n}[2 p+$ $2(1-p) \mu]$, is lower than the one for broad bracketing, $\hat{a}_{b}\left[2 p-p^{2}+(1-p)^{2} \mu\right]$. Using $\hat{a}_{b}=\frac{\hat{a}_{n}}{1-p}$ and rearranging:

$$
\frac{1}{1-p} \geq \frac{2 p+2(1-p) \mu}{2 p-p^{2}+(1-p)^{2} \mu}
$$

Rearranging again then shows that

$$
U_{0}\left(\hat{a}_{n}, \hat{a}_{n} ; \bar{e}_{1}, \bar{e}_{2}\right) \geq U_{0}\left(\hat{a}_{b} ; \bar{e}_{1}, \bar{e}_{2}\right) \Leftrightarrow p^{2}-(1-p)^{2} \mu \geq 0 .
$$

Exploiting the monotonicity of the utility functions in $\beta$ (which follows from $\frac{\partial}{\partial \beta} \hat{a}_{b}<0$, and $\frac{\partial}{\partial \beta} \hat{a}_{n}<0$, respectively), we obtain another equivalence relation in terms of the respective minimum level of the present bias parameter for which an "easy" broad goal or narrow goals are feasible:

$$
U_{0}\left(\hat{a}_{n}, \hat{a}_{n} ; \bar{e}_{1}, \bar{e}_{2}\right) \geq U_{0}\left(\hat{a}_{b} ; \bar{e}_{1}, \bar{e}_{2}\right) \quad \Leftrightarrow \quad p^{2}-(1-p)^{2} \mu \geq 0 \quad \Leftrightarrow \quad \beta_{b} \geq \beta_{n} .
$$

\section{A.7 Derivation of $\hat{a}_{b}^{\text {info }}$ [Equation (12)]}

There is an asymmetric effort response of self 2, depending on the outcome in the first task: $\bar{e}_{2}\left(\underline{y}_{1}\right)$ and $\underline{e}_{2}\left(\bar{y}_{1}\right)$. So the incentive constraint of self 1 is:

$$
\begin{aligned}
& \beta a_{b}(\mu-1)[\underbrace{\operatorname{Pr}\left(\operatorname{loss} \mid \underline{e}_{1}, \bar{e}_{2}\left(\underline{y}_{1}\right), \underline{e}_{2}\left(\bar{y}_{1}\right)\right)-\operatorname{Pr}\left(\operatorname{loss} \mid \bar{e}_{1}, \bar{e}_{2}\left(\underline{y}_{1}\right), \underline{e}_{2}\left(\bar{y}_{1}\right)\right)}_{=1-p-(1-p)^{2}=p(1-p)}] \\
& \geq \quad c-\beta p \bar{y}+[\beta(p \bar{y}-c)-\beta(1-p)(p \bar{y}-c)] .
\end{aligned}
$$

The goal that makes this incentive constraint just bind is:

$$
\hat{a}_{b}^{\text {info }}=\frac{c-\beta p \bar{y}+\beta p(p \bar{y}-c)}{\beta p(1-p)(\mu-1)} .
$$

Subtracting $\hat{a}_{b}$ from $\hat{a}_{b}^{\text {info }}$

$$
\hat{a}_{b}^{\text {info }}-\hat{a}_{b}=\frac{p \bar{y}-c}{(1-p)(\mu-1)},
$$

and using $\hat{a}_{b}=\frac{\hat{a}_{n}}{1-p}$ gives 12 .

\section{A.8 Proof of Lemma 5}

See Section 5.2 . 


\section{A.9 Proof of Proposition 2}

\section{i) A "difficult" broad goal $\bar{y}<a_{b} \leq 2 \bar{y}$ is never optimal}

The utility for self 0 from setting narrow goals is the same for the no-information and information scenario. Abstaining from goal setting yields self 0 utility of zero. To obtain an upper bound on the (normalized) utility of self 0 with a "difficult" broad goal, set $a_{b}^{d}=\bar{y}$ (recall that $\frac{\partial}{\partial a} U_{0}\left(a ; e_{1}, e_{2}\right)<0$ for fixed $\left.e_{1}, e_{2}\right)$, and suppose that self 1 and 2 provide high effort (if they do not, the utility of self 0 can only be lower):

$$
U_{0}\left(\bar{y} ; \bar{e}_{1}, \bar{e}_{2}\right) / \beta=\bar{y}\left[p^{2}-(1-p)^{2} \mu\right]-2 c .
$$

Hence, a necessary condition for a difficult broad goal to do strictly better than no goal is that

$$
p^{2}-(1-p)^{2} \mu>0 \text {. }
$$

Given that, for fixed effort levels, the utility is decreasing in the goal level, we also know that $U_{0}\left(\bar{y} ; \bar{e}_{1}, \bar{e}_{2}\right) \leq U_{0}\left(\hat{a}_{b} ; \bar{e}_{1}, \bar{e}_{2}\right)$. Therefore, the equivalence relation from (16) tells us that a necessary condition for any type of broad goal to do strictly better than narrow goals is that

$$
p^{2}-(1-p)^{2} \mu<0 \text {. }
$$

But the two necessary conditions for a difficult broad goal to be optimal conflict with each other. For example, if Condition (18) holds, Condition (17) is violated and tells us that the utility from the goal is negative; this means that setting no goal is preferred over setting a difficult broad goal. So whenever narrow goals are feasible (i.e., if $\frac{1}{\mu} \beta_{s c} \leq \beta$ ), either narrow goals dominate a difficult broad goal, or setting no goal is optimal. As argued in the proofs of Lemma 1 and 3 , at $\beta=\frac{1}{\mu} \beta_{s c}$ we have $U_{0}\left(\bar{y} ; \bar{e}_{1}, \bar{e}_{2}\right)<0$. This is the upper bound on the profit of a difficult broad goal for $\beta<\frac{1}{\mu} \beta_{s c}$ as well, because for any type of broad goal $\frac{\partial}{\partial \beta} U_{0}\left(a ; \bar{e}_{1}, \bar{e}_{2}\right)>0$. Taken together this shows that a difficult broad goal can never be optimal.

\section{ii) An "easy" broad goal $a_{b} \leq \bar{y}$ is never optimal}

The (normalized) expected utility of self 0 from setting narrow goals is:

$$
U_{0}\left(\hat{a}_{n}, \hat{a}_{n} ; \bar{e}_{1}, \bar{e}_{2}\right) / \beta=2(p \bar{y}-c)-\hat{a}_{n}[2 p+2(1-p) \mu] .
$$

For the "easy" broad goal the utility can be written as:

$$
\begin{aligned}
U_{0}\left(\hat{a}_{b}^{\text {info }} ; \bar{e}_{1}, \bar{e}_{2}\right) / \beta & =(2-p)(p \bar{y}-c)-\hat{a}_{b}^{\text {info }}\left[2 p-p^{2}+(1-p)^{2} \mu\right] \\
& =(2-p)(p \bar{y}-c)-\left[\hat{a}_{b}+\frac{p \bar{y}-c}{(1-p)(\mu-1)}\right]\left[2 p-p^{2}+(1-p)^{2} \mu\right] \\
& =(2-p-\kappa)(p \bar{y}-c)-\hat{a}_{b}\left[2 p-p^{2}+(1-p)^{2} \mu\right],
\end{aligned}
$$


where $\kappa \equiv \frac{2 p-p^{2}+(1-p)^{2} \mu}{(1-p)(\mu-1)}$, and we use from $\sqrt{12}$ that $\hat{a}_{b}^{\text {info }}=\hat{a}_{b}+\frac{p \bar{y}-c}{(1-p)(\mu-1)}$. Substituting $\hat{a}_{n}=(1-p) \hat{a}_{b}$ we obtain:

$$
\begin{array}{ll} 
& U_{0}\left(\hat{a}_{n}, \hat{a}_{n} ; \bar{e}_{1}, \bar{e}_{2}\right)-U_{0}\left(\hat{a}_{b}^{\text {info }} ; \bar{e}_{1}, \bar{e}_{2}\right) \geq 0 \\
\Leftrightarrow \quad & (p+\kappa)(p \bar{y}-c)-\hat{a}_{b}\left[(1-p)^{2} \mu-p^{2}\right] \geq 0 .
\end{array}
$$

Thus, if $p^{2}-(1-p)^{2} \mu \geq 0$ we know that $U_{0}\left(\hat{a}_{n}, \hat{a}_{n} ; \bar{e}_{1}, \bar{e}_{2}\right)-U_{0}\left(\hat{a}_{b}^{\text {info }} ; \bar{e}_{1}, \bar{e}_{2}\right)$ is strictly positive. This is exactly the condition from Proposition 1. so whenever narrow bracketing is optimal in the no-information scenario, it is also optimal in the information scenario.

Now suppose $p^{2}-(1-p)^{2} \mu<0$. We will now see that $U_{0}\left(\hat{a}_{b}^{\text {info }} ; \bar{e}_{1}, \bar{e}_{2}\right) \geq 0$ implies $U_{0}\left(\hat{a}_{n}, \hat{a}_{n} ; \bar{e}_{1}, \bar{e}_{2}\right)-U_{0}\left(\hat{a}_{b}^{\text {info }} ; \bar{e}_{1}, \bar{e}_{2}\right) \geq 0$, i.e., whenever a broad goal would yield a positive utility, it is dominated by narrow bracketing. For this we show that

$$
U_{0}\left(\hat{a}_{n}, \hat{a}_{n} ; \bar{e}_{1}, \bar{e}_{2}\right)-U_{0}\left(\hat{a}_{b}^{\text {info }} ; \bar{e}_{1}, \bar{e}_{2}\right) \geq U_{0}\left(\hat{a}_{b}^{\text {info }} ; \bar{e}_{1}, \bar{e}_{2}\right) .
$$

Comparing (19) and (20), note first that $\hat{a}_{b}\left[(1-p)^{2} \mu-p^{2}\right] \leq \hat{a}_{b}\left[2 p-p^{2}+(1-p)^{2} \mu\right]$. Second, note that $(p+\kappa)(p \bar{y}-c) \geq(2-p-\kappa)(p \bar{y}-c) \Leftrightarrow \kappa \geq 1-p$. The result in (21) follows because

$$
\kappa \equiv \frac{2 p-p^{2}+(1-p)^{2} \mu}{(1-p)(\mu-1)} \geq 1-p \quad \Leftrightarrow \quad 2 p-p^{2}+(1-p)^{2} \mu \geq(1-p)^{2}(\mu-1),
$$

where the latter inequality clearly holds.

\section{B The simultaneous-tasks scenario}

In Section 4, a broad goal $a_{b} \leq \bar{y}$ gives rise to a leaning-back effect, according to which self 1 can substitute effort on the first task with (for self 1 less painful) effort by self 2 on the second task. What if the individual works on the two tasks simultaneously? The difference with the no-information scenario is that both effort costs are felt at the same time, and we therefore have two incentive constraints. Providing effort in both tasks must be better than providing effort in just one task:

$$
\begin{aligned}
& a_{b} \beta(\mu-1)[\underbrace{\operatorname{Pr}\left(\operatorname{loss} \mid \underline{e}_{j}, \bar{e}_{i}\right)-\operatorname{Pr}\left(\operatorname{loss} \mid \bar{e}_{j}, \bar{e}_{i}\right)}_{p(1-p)}] \geq c-\beta p \bar{y} \\
\Leftrightarrow \quad & a_{b} \geq \frac{c-\beta p \bar{y}}{\beta p(\mu-1)(1-p)} \equiv \hat{a}_{b},
\end{aligned}
$$

because this corresponds exactly to the relevant incentive constraint in the no-information scenario [Equation (9)]. And providing effort in both tasks must also be better than shirking in both tasks:

$$
\begin{aligned}
& \beta a_{b}(\mu-1)[\underbrace{\operatorname{Pr}\left(\operatorname{loss} \mid \underline{e}_{j}, \underline{e}_{i}\right)-\operatorname{Pr}\left(\operatorname{loss} \mid \bar{e}_{j}, \bar{e}_{i}\right)}_{p(2-p)}] \geq 2(c-\beta p \bar{y}) \\
\Leftrightarrow & a_{b} \geq \frac{c-\beta p \bar{y}}{\beta p(\mu-1)\left(1-\frac{p}{2}\right)} \equiv \breve{a} .
\end{aligned}
$$


To satisfy both incentive constraints, $a_{b} \geq \max \left\{\hat{a}_{b}, \breve{a}\right\}=\hat{a}_{b}$. So $\hat{a}_{b}^{s i m}=\hat{a}_{b}$ from Equation (9), and the results from the no-information scenario carry over.

To gain some intuition for why the the "prevent-shirking-in-one-task" incentive constraint is the binding one, consider first the effort cost side (net of the present-bias discounted expected benefit from the task outcome). If, instead of working hard in both tasks, self 1 were to shirk in one task he would gain $c-\beta p \bar{y}$; and if he were to shirk in both tasks he would gain twice that amount, $2(c-\beta p \bar{y})$. But shirking exposes him to the risk of falling short of the goal. Consider this side now. Intuitively, by not working at all, the individual would definitely fall short of the goal and suffer a loss. In contrast, putting in effort in one of the two tasks already goes some way toward avoiding this: with probability $p$ the task outcome is high, and this is enough to satisfy the easy broad goal. So the difference from working hard in both tasks is not that big anymore. More specifically, shirking only in one task would increase the probability of a loss by $\operatorname{Pr}(\operatorname{loss} \mid \underline{e}, \bar{e})-\operatorname{Pr}(\operatorname{loss} \mid \bar{e}, \bar{e})=p(1-p)$, whereas shirking in both tasks would increase by more than twice that amount the probability of a loss: $\operatorname{Pr}(\operatorname{loss} \mid \underline{e}, \underline{e})-\operatorname{Pr}(\operatorname{loss} \mid \bar{e}, \bar{e})=p(2-p)>2 p(1-p)$.

Putting both sides together, we thus see that the risk of falling short of the goal is proportionately larger relative to the net cost of effort in the case of shirking in both tasks. As a result, the "prevent-shirking-in-one-task" incentive constraint is the binding one. 


\section{References}

Abeler, J., A. Falk, L. Götte, and D. Huffman (2009): "Reference Points and Effort Provision," IZA Discussion Paper no. 3939.

Ainslie, G., and N. Haslam (1992): "Hyperbolic Discounting," in Choice over Time, ed. by G. Loewenstein, and J. Elster, pp. 57-92. Russell Sage Foundation, New York.

BandurA, A. (1989): "Human Agency in Social Cognitive Theory," American Psychologist, 44(9), 1175-1184.

Barberis, N. (2001): "Mental Accounting, Loss Aversion, and Individual Stock Returns," Journal of Finance, 56(4), 1247-1292.

BArGH, J. A. (1990): "Auto-motives: Preconscious Determinants of Social Interaction," in Handbook of Motivation and Cognition: Foundations of Social Behavior, ed. by E. T. Higgins, and R. M. Sorrentino, vol. 2, pp. 93-130. Guilford Press, New York.

Bénabou, R., And J. Tirole (2004): "Willpower and Personal Rules," Journal of Political Economy, 112(4), 848-886.

Benartzi, S., and R. H. Thaler (1995): "Myopic Loss Aversion and the Equity Premium Puzzle," Quarterly Journal of Economics, 110(1), 73-92.

Benhabib, J., And A. Bisin (2005): "Modeling Internal Commitment Mechanisms and Self-Control: A Neuroeconomics Approach to Consumption-Saving Decisions," Games and Economic Behavior, 52(2), 460-492.

Brocas, I., J. D. Carrillo, and M. Dewatripont (2004): "Commitment Devices under Self-control Problems: An Overview," in Reasons and Choices, ed. by I. Brocas, and J. D. Carrillo, vol. 2 of The Psychology of Economic Decisions, chap. 4, pp. 49-66. Oxford University Press, Oxford.

Camerer, C., L. Babcock, G. Loewenstein, and R. Thaler (1997): "Labor Supply of New York City Cabdrivers: One Day at a Time," Quarterly Journal of Economics, 112(2), 407-41.

Carver, C. S., And M. F. Scheier (1999): "Themes and Issues in the Self-regulation of Behavior," in Advances in Social Cognition, ed. by R. S. Wyer, vol. 12, pp. 1-105. Erlbaum, Mahwah, NJ.

Cicchetti, C. J., And J. A. Dubin (1994): "A Microeconometric Analysis of Risk Aversion and the Decision to Self-Insure," Journal of Political Economy, 102(1), 169-86. 
Crawford, V., And J. Meng (2008): "New York City Cabdrivers' Labor Supply Revisited: Reference-Dependence Preferences with Rational-Expectations Targets for Hours and Income," University of California at San Diego, Economics Working Paper No 200803.

Elster, J. (2000): Ulysses Unbound: Studies in Rationality, Precommitment, and Constraints. Cambridge University Press, Cambridge, MA.

Falk, A., And M. Knell (2004): "Choosing the Joneses: Endogenous Goals and Reference Standards," Scandinavian Journal of Economics, 106(3), 417-435.

FARBer, H. (2005): "Is Tomorrow Another Day? The Labor Supply of New York City Cabdrivers," Journal of Political Economy, 113(1), 46-82.

(2008): "Reference-Dependent Preferences and Labor Supply: The Case of New York City Taxi Drivers," American Economic Review, 98(3), 1069-1082.

Fehr, E., And L. Götte (2007): "Do Workers Work More if Wages are High? Evidence from a Randomized Field Experiment," American Economic Review, 97(1), 298-317.

Fuhrmann, A., And J. Kuhl (1998): "Maintaining a Healthy Diet: Effects of Personality and Self-reward versus Self-punishment on Commitment to and Enactment of Self-chosen and Assigned Goals," Psychology \& Health, 13(4), 651-686.

Gneezy, U., And J. Potters (1997): "An Experiment on Risk Taking and Evaluation Periods," Quarterly Journal of Economics, 112(2), 631-45.

Goette, L., D. Huffman, And E. Fehr (2004): "Loss Aversion and Labor Supply," Journal of the European Economic Association, 2(2-3), 216-228.

Gollwitzer, P. M. (1999): "Implementation Intentions: Strong Effects of Simple Plans," American Psychologist, 54(7), 493-503.

Hardie, B., E. Johnson, And P. Fader (1993): "Modeling Loss Aversion and Reference Dependence Effects on Brand Choice," Marketing Science, 12(4), 378-394.

Heath, C., R. P. Larrick, and G. Wu (1999): "Goals as Reference Points," Cognitive Psychology, 38, 79-109.

Heath, C., and J. B. Soll (1996): "Mental Budgeting and Consumer Decisions," Journal of Consumer Research: An Interdisciplinary Quarterly, 23(1), 40-52.

Herrnstein, R. J., And D. Prelec (1991): "Melioration: A Theory of Distributed Choice," Journal of Economic Perspectives, 5(3), 137-156. 
Herweg, F., And D. Müller (2008): "Performance of Procrastinators: On the Value of Deadlines," mimeo, University of Bonn.

HsiAw, A. (2009a): "Goal Bracketing and Self-control," work in progress.

(2009b): "Goal-Setting, Social Comparison, and Self-control," mimeo, Princeton University.

Kahneman, D., and D. Lovallo (1993): "Timid Choices and Bold Forecasts: A Cognitive Perspective on Risk Taking," Managent Science, 39(1), 17-31.

Kahneman, D., And A. Tversky (1979): "Prospect Theory: An Analysis of Decision under Risk," Econometrica, 47(2), 263-292.

Koch, A. K., And J. NAfziger (2008): "Self-regulation Through Goal Setting," IZA Discussion Paper no. 3893.

— (2009): "Self-rewards and Personal Motivation," Working Paper, Aarhus University.

KÖszegi, B., And M. Rabin (2006): "A Model of Reference-Dependent Preferences," Quarterly Journal of Economics, 121(4), 1133-1165.

LaIBson, D. (1997): "Golden Eggs and Hyperbolic Discounting," Quarterly Journal of Economics, 112(2), 443-477.

Locke, E. A., and G. P. Latham (1990a): A Theory of Goal Setting \& Task Performance. Prentice Hall, Englewood Cliffs, NJ.

(1990b): "Work Motivation and Satisfaction: Light at the End of the Tunnel," Psychological Science, 1(4), 240-246.

(2002): "Building a Practically Useful Theory of Goal Setting and Task Motivation," American Psychologist, 57(9), 705717.

Odean, T. (1998): "Are Investors Reluctant to Realize Their Losses?," Journal of Finance, 53(5), 1775-1798.

O’Donoghue, T., And M. Rabin (1999): "Doing It Now or Later," American Economic Review, 89(1), 103-124.

Oettingen, G., H.-J. Pak, and K. Schnetter (2001): "Self-Regulation of Goal Setting: Turning Free Fantasies About the Future Into Binding Goals," Journal of Personality and Social Psychology, 80(5), 736-753.

Phelps, E. S., and R. A. Pollak (1968): "On Second-Best National Saving and GameEquilibrium Growth," Review of Economic Studies, 35(2), 185-199. 
Rabin, M., And G. Weizsäcker (2009): "Narrow Bracketing and Dominated Choices," American Economic Review, forthcoming.

Read, D., G. Loewenstein, and M. Rabin (1999): "Choice Bracketing," Journal of Risk and Uncertainty, 19(1-3), 171-97.

Simonson, I. (1990): "The Effect of Purchase Quantity and Timing on Variety Seeking Behaviour," Journal of Marketing Research, 32, 150-162.

Strotz, R. H. (1955): "Myopia and Inconsistency in Dynamic Utility Maximization," Review of Economic Studies, 23(3), 165-180.

Suvorov, A., And J. van de Ven (2008): "Goal Setting as a Self-Regulation Mechanism," Working Papers w0122, Center for Economic and Financial Research (CEFIR).

Thaler, R. (1980): "Toward a Positive Theory of Consumer Choice," Journal of Economic Behavior \& Organization, 1(1), 39-60.

(1999): "Mental Accounting Matters," Journal of Behavioral Decision Making, 12, 183-206.

Thaler, R., A. Tversky, D. Kahneman, and A. Schwartz (1997): "The Effect of Myopia and Loss Aversion on Risk Taking: An Experimental Test," Quarterly Journal of Economics, 112(2), 647-61.

Thaler, R. H. (1985): "Mental Accounting and Consumer Choice," Marketing Science, $4(3), 199-214$.

Thaler, R. H. (1990): "Saving, Fungibility, and Mental Accounts," Journal of Economic Perspectives, 4(1), 193-205.

Thaler, R. H., And H. M. Shefrin (1981): "An Economic Theory of Self-control," Journal of Political Economy, 89(2), 392-406.

Tversky, A., And D. Kahneman (1981): "The Framing of Decisions and the Psychology of Choice," Science, New Series, 211(4481), 453-458. 